\title{
Youth health: a challenge for primary care
}

World Health Organization (WHO) tells us that in 2009 over eight million children under the age of five years died worldwide (WHO, 2010). Ninety percent of the deaths result from neonatal conditions, pneumonia, diarrhea, malaria, measles, and HIV/AIDS. Developed countries manifest different major causes of death such as mental health conditions leading to suicide and homicide, as well as injuries from car crashes and poisoning (Centers for Disease Control and Prevention, 2011). Other lifestyle behaviors such as obesity, inactivity, and substance use lead to chronic health conditions as children reach adolescence and young adulthood.

How can health-care providers influence morbidity and mortality rates, and promote health for a greater number of children? Primary health care is the organizing principle that can lead to improved child health, strengthen health-care systems, and nurture children in body and mind. Primary health-care research often excludes youth, when such investigations could result in information to improve health care for generations to come. WHO provides recommendations about critical elements of primary health care (WHO, 2011). Let us examine each strategy and its potential applications to research involving youth:

- Reduce exclusion and social disparities

Certain cultural and ethnic groups suffer disproportionally high disease burden and shorter lives because of increased likelihood of acute and chronic disease. Primary care is a 'leveler' of access and health within populations, mitigating the effects of low income and ethnicity on health status (Starfield et al., 2005). Diarrhea, respiratory infections, obesity, low birth weight, injury, diabetes, and mental health disruptions are examples of conditions associated with social/ cultural determinants of health. Tracking morbidity and mortality statistics and careful documentation of outcomes for primary care interventions

Correspondence to: Dr Ruth Bindler, Washington State University, Spokane, WA, USA. Email: bindler@wsu.edu

(C) Cambridge University Press 2011 ensure that the best evidence will be integrated. For example, programs that deal with reproductive timing can impact infant mortality and child abuse rates (McClaine and Garcia, 2011), and pregnant women in a pregnancy management program showed improved birth outcomes with less likelihood of having low-birth-rate infants (Mason et al., 2011). Similarly, the National Child Development Study in Great Britain found that childhood socio-economic position is associated with adult smoking behaviors, suggesting the importance of primary care interventions to improve social determinants of health (Lacey et al., 2010).

- Organize health services around people's needs

Community assessments should precede new models for care provision, and questions such as incidence, prevalence, and existing services must be examined. Areas will emerge that suggest need for services. For example, most communities in developing and developed countries manifest a disproportionate number of youth affected by mental disorders. Mood, behavior, and anxiety disorders are common, whether related to high levels of daily stress, chronic war, or other causes (Merikangas et al., 2010). Most families find it difficult to access services when they are traditionally available. Approaches such as community health workers, Internet, teaching videos, phone calls, informational kiosks at stores, and other creative and novel approaches are needed. An example of an evidence-based, creative, and novel intervention is the Keep Your Children/ Yourself Safe and Secure (KySS) campaign, a public awareness and educational program that promotes integrated physical and mental health care for children in adolescence in conjunction with the US National Association of Pediatric Nurse Practitioners (KySS, n.d.).

- Integrate health care into all sectors

Children are typically found in their homes, infant and child care centers, schools, community centers, faith-based facilities, and sports activities. However, few primary health-care offerings are 
organized to bring health care to children and their families in these settings. Schools have been suggested as an excellent venue for primary care delivery to children (WHO, 2009). The Teen Eating and Activity Mentoring in Schools project in the United States has been effective in improving nutrition and physical activity for middle school students (Adamson et al., 2010; Power et al., 2010; Bindler and Daratha, 2011). The US National Assembly on School-Based Health Care (2011) supports a grant program to improve primary care provision in schools. Ongoing research through this assembly can determine the best locations, hours, and types of care to maximize effectiveness. Linking such care to shared electronic health records and measuring outcomes for youth will promote the best practices for care provision.

\section{- Provide collaborative models of policy dialog}

Health-care provision is no longer the sole prerogative of physicians or any other one type of provider. Interprofessional collaborations of physicians, nurses, dentists, psychologists, pharmacists, nutritionists, and other providers are needed to supply comprehensive care that is most likely to influence chronic disease outcomes, mental and physical conditions, and other major conditions affecting children. WHO used a multiple case study approach to interview key informants in all six WHO regions. Recommendations were made for a Framework of Action applicable to all countries, which includes political action and legislation to promote collaboration among disciplines, and application of interprofessional education (Mickan et al., 2010). Canadian researchers have found that interdisciplinary health-care teams in primary care settings lead to increased access, improved range of services, and positive provider/patient satisfaction (Petoukhov et al., n.d.). Similarly, Australia's support of interdisciplinary primary health-care research is providing key information about the best ways to improve primary health-care interdisciplinary teamwork (Australian Primary Health Care Research Institute, 2011).

- Increase stakeholder participation

Often, care providers decide the needs of children and families and proceed to provide the 'needed' services. However, the children and families themselves may have a very different perspective of their needs and do not take advantage of the provided services. Community engagement is essential for successful programs, and community-based participatory research (CBPR) is an approach that ensures the engagement of participants. Research should be preceded by environmental, geospatial, and readiness to change assessments. One such approach is the Community Readiness Model at the Tri-Ethnic Center for Prevention Research that provides tools to assess the readiness of communities for sustainable preventive activities (Findholt, 2007; Stanley and Edwards, n.d.). CBPR empowers individuals and communities themselves to build community capacity and promote social change. This approach has been successful in engaging American Indian and Alaskan Native populations in building primary health-care approaches (Katz et al., 2011). Efforts to implement youth violence prevention programs have found that community mobilization and engagement are critical to delivering evidence-based strategies (Azrael and Hemenway, 2011; Miao et al., 2011).

Primary health care has a proven record of contributions to strengthening health in a costeffective manner, eliminating income and ethnic/ racial disparities, and integrating care into extant systems. To improve health of youth, evidencebased practice demands development of tools by primary care research networks, application of primary care evidence, and exportation of models of care for continued effectiveness testing in a variety of settings (Bleeker et al., 2010; Kruk et al., 2010).

\section{Ruth Bindler \\ Washington State University Spokane, WA, USA}

\section{References}

Adamson, K., Daratha, K. and Bindler, R. 2010: Dietary quality among early adolescents and associations with health indicators. Infant, Child and Adolescent Nutrition 2, 158-64.

Australian Primary Health Care Research Institute. 2011: Interdisciplinary and/or cross boundary primary health care research. Retrieved 6 September 2011 from http://www.anu.edu. au/aphcri/Spokes_Research_Program/2010_Intersectoral_ Boundaries.php 
Azrael, D. and Hemenway, D. 2011: Greater than the sum of their parts: the benefits of youth violence prevention centers. American Journal of Community Psychology 48, 21-30.

Bindler, R. and Daratha, K. 2011: Relationship of weight status, gender, and cardiometabolic outcomes for adolescents in the TEAMS study. Biological Research in Nursing, doi: 10.1177/1099800410397179.

Bleeker, J.M., Stalman, W.A. and van der Horst, H.E. 2010: Evaluating primary care research networks: a review of currently available tools. Journal of the American Board of Family Medicine 23, 465-75.

Centers for Disease Control and Prevention. 2011: Data and statistics. Retrieved 6 September 2011 from http://www.cdc.gov

Findholt, N. 2007: Application of the Community Readiness Model for childhood obesity prevention. Public Health Nursing 24, 565-70.

Katz, J.R., Martinez, T.A. and Paul, R. 2011: Community based participatory research and American Indian/Alaska Native nurse practitioners: a partnership to promote adolescent health. Journal of American Academy of Nurse Practitioners 23, 298-304.

Kruk, M.E., Porignon, D., Rockers, P.C. and Van Lerberghe, W. 2010: The contribution of primary care to health and health systems in low- and middle-income countries: a critical review of major primary care initiatives. Social Science Medicine 70, 904-11.

Keep Your Children/Yourself Safe and Secure (KySS; n.d.). Integrating physical and mental health care for young people. Retrieved 12 January 2011 from http://www.aannet. org/files/public/KySS_template.pdf

Lacey, R.E., Cable, N., Stafford, M., Bartley, M. and Pikhart, H. 2010: Childhood socio-economic position and adult smoking: are childhood psychosocial factors important? Evidence from a British birth cohort. European Journal of Public Health, doi: 10.1093/eurpub/ckq179.

Mason, M.V., Poole-Yeager, A., Lucas, B., Krueger, C.R., Ahmed, T. and Duncan, I. 2011: Effects of a pregnancy management program on birth outcomes in managed Medicaid. Managed Care 20, 39-46.

McClaine, R.J. and Garcia, V.F. 2011: Unnatural causes: social determinants of child health and well-being. Archives of Pediatrics and Adolescent Medicine 165, 476.
Merikangas, K.R., He, J., Burstein, M., Swanson, S.A., Avenevoli, S., Cui, L., Benjet, C., Beorgiades, K. and Swendsen, J. 2010: Lifetime prevalence of mental disorders in U.S. adolescents: results from the National Comorbidity Study - Adolescent Supplement (NCS-A). Journal of the American Academy of Child and Adolescent Psychiatry 49, 980-89.

Mickan, S., Hoffman, S.J., Nasmith, L. and World health Organizations Study Group on Interprofessional Education and Collaborative Practice. 2010: Collaborative practice in a global health context: common themes from developed and developing countries. Journal of Interprofessional Care 24, 492-502.

Miao, T.A., Umemoto, K., Gonda, D. and HIshinuma, E.S. 2011: Essential elements for community engagement in evidence-based youth violence prevention. American Journal of Community Psychology 48, 120-32.

National Assembly on School-Based Health Care. 2011: NASBHC. Retrieved 27 May 2011 from http://www.nasbhc. org/site/c.jsJPKWPFJrH/b.2554077/k.BEE7/Home.htm

Petoukhov, K., Edwards, J. and Steele, A. (n.d.). Measuring the effectiveness of interdisciplinary health care teams in a primary care setting: a review of published evidence. Winnipeg: Manitoba Health, 1-58.

Power, T., Bindler, R., Goetz, S. and Daratha, K. 2010: Obesity prevention in early adolescence: student, parent, and teacher views. Journal of School Health 8, 13-19.

Stanley, L. and Edwards, R. (n.d.). Community readiness. Retrieved 12 January 2011 from http://www.triethniccenter. colostate.edu/community readiness.shtml

Starfield, B., Shi, L. and Macinko, J. 2005: Contribution of primary care to health systems and health. Milbank Quarterly 83, 457-502.

World Health Organization. 2009: Global school health initiative. Retrieved 6 September 2011 from http://www.int/topics/ millenium_development_goals/child_mortality/en/

World Health Organization. 2010: Child health. Retrieved 6 September 2011 from http://www.int/topics/millenium_ development_goals/child_mortality/en/

World Health Organization. 2011: Primary health care. Retrieved 6 September 2011 from http://www.int/topics/millenium_ development_goals/child_mortality/en/ 